\title{
Transition Metal Chelates as Accelerators for Epoxy Resin Systems-Studies with Cobalt (III) Acetylacetonate
}

\author{
P. V. REDDY, R. THIAGARAJAN and M. C. RATRA, Central Power \\ Research Institute, Bangalore-560 094 and N. M. NANJE GOWDA, \\ Department of Chemistry, Central College, Bangalore University, \\ Bangalore-560 001, India
}

\begin{abstract}
Synopsis
Cobalt (III) acetylacetonate serves as an accelerator for anhydride curable epoxy resin system and the rate of curing is found to increase with enhanced concentrations of the metal chelate. There is also an appreciable reduction in the cure gel time. Kinetic studies based on thermal analytical techniques reveal that the overall curing process follows first order kinetics. Based on the kinetic results a cure schedule has been proposed. It is also observed that the electrical, mechanical, and thermal properties of the cured epoxy system are not altered by the presence of the metal chelate at the concentration studied.
\end{abstract}

\section{INTRODUCTION}

The development of a suitable accelerator for anhydride cured epoxy resin systems at moderately elevated temperatures has received considerable attention of several industrial laboratories. The accelerators are chosen in such a manner that the storage life of the catalysed resin system so developed should not be affected appreciably. Furthermore, the rate of curing of such a system should be reasonably high and the ultimate properties of the cured epoxy system should remain unaltered even at elevated temperatures. ${ }^{1}$

In the recent past several latent accelerators such as quaternary ammonium halides, ${ }^{2}$ siliconate salts, ${ }^{3}$ triethanolamineborate,${ }^{4}$ triethanolamine titanate,$^{5}$ quaternary phosphonium, ${ }^{6}$ and arsonium salts ${ }^{7}$ have been used as accelerators for anhydride cured epoxy impregnants. However, these compounds fail to fulfil some of the aforesaid conditions. Though commercial boron trifluoridemonoethylamine complex serves as a better catalyst for bisphenol-A based epoxy systems, ${ }^{8}$ the major setback being its poor electrical properties at elevated temperatures. Hence, the need for suitable accelerators has been greatly felt in the field of electrical applications.

There are patents which reveal that organometallic compounds have been used as curing agents for various epoxy systems..$^{9-11}$ Recently, it has been observed that several metal acetyl acetonates act as latent accelerators for anhydride cure of bisphenol-A based resins. ${ }^{1,12-15}$ However these reports do not indicate kinetic features of these resins in presence of the metal chelate. It is in this perspective a systematic study is undertaken to examine the feasibility of using metal chelates as accelerators for bisphenol-A based epoxy system and 


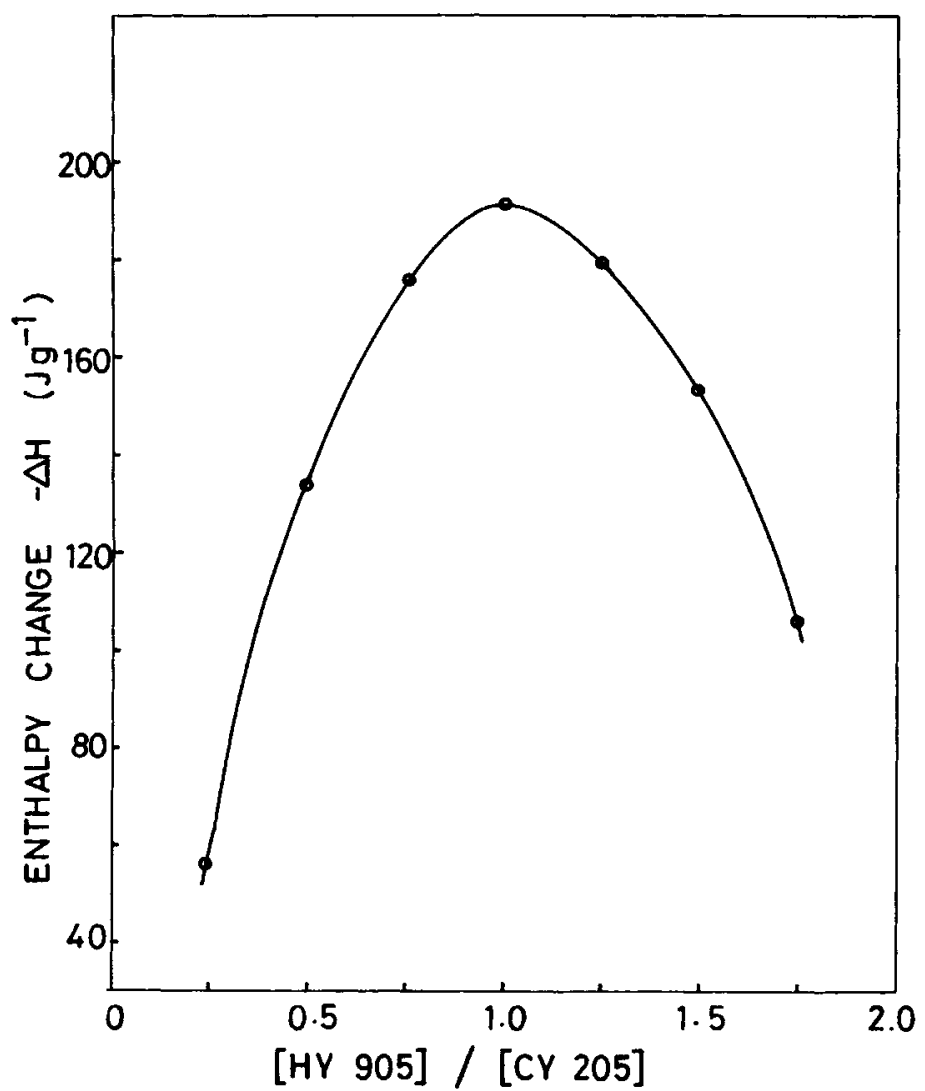

Fig. 1. Enthalpy change data for different concentrations of hardener with bisphenol-A based resin.

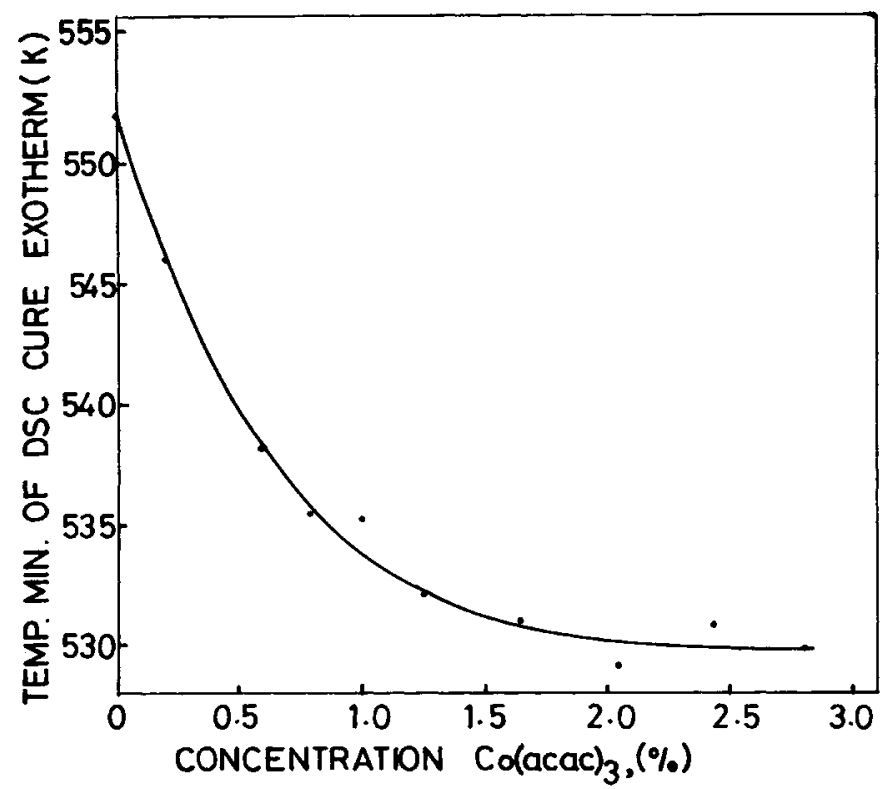

Fig. 2. Effect of Co( acac $)_{3}$ on $T_{\min }$ of DSC cure exotherm for bisphenol-A based epoxy resin with anhydride hardener. 
TABLE I

Gel Time and Storage Data for Epoxy-Anhydride Resin System with Different Concentrations of $\mathrm{Co}(\text { acac })_{3}$

\begin{tabular}{cccccc}
\hline & \multicolumn{3}{c}{$\begin{array}{c}\text { Gel time data (min)* at } \\
\text { temperature (K) }\end{array}$} \\
\cline { 2 - 5 } $\begin{array}{c}\text { Concentration } \\
\text { of Co(acac) } \\
(\%)\end{array}$ & 398 & 408 & 428 & 448 & Catalysed storage \\
life time (days)
\end{tabular}

* On $10 \mathrm{~g}$ impregnant sample in a test tube with a movable spiral wire.

† Time for viscosity to reach from $1500 \mathrm{cps}$ to $10000 \mathrm{cps}$ at $298 \mathrm{~K}$.

the results obtained with cobalt (III) acetylacetonate, $\mathrm{Co}(\mathrm{acac})_{3}$, are reported in this paper.

\section{EXPERIMENTAL}

Diglycidyl ether of bisphenol-A (DGEBA, CY 205) and anhydride hardener (HY 905), procured from CIBA-GEIGY India Ltd., are used as such. $W_{12}$ grade silica floor of 300 mesh also from CIBA-GEIGY is dried at $383 \mathrm{~K}$ for $3 \mathrm{~h}$ and then used as the filler. Co (acac $)_{3}$ is prepared and characterised as per the procedure described elsewhere. ${ }^{16}$

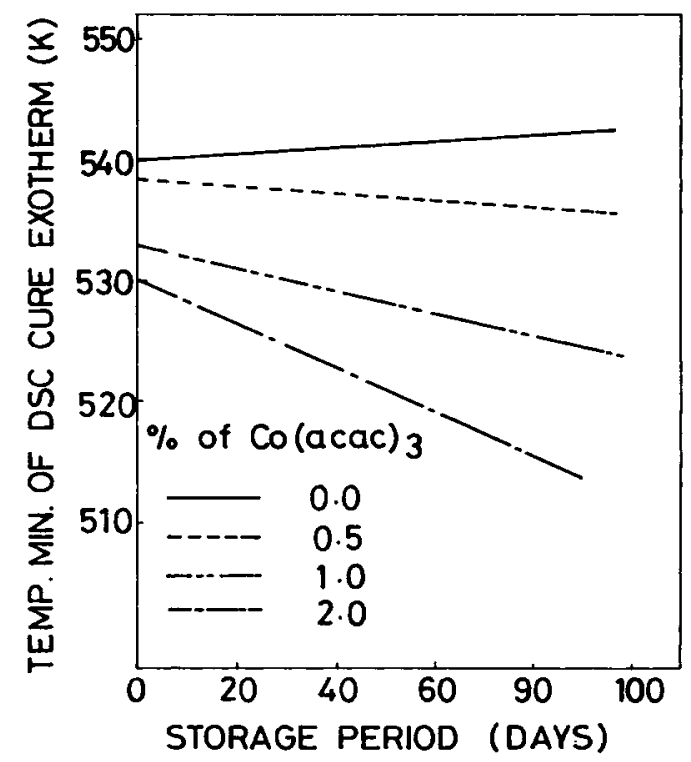

Fig. 3. Effect of $\mathrm{Co}(\mathrm{acac})_{3}$ on the storage life of the catalysed system. 


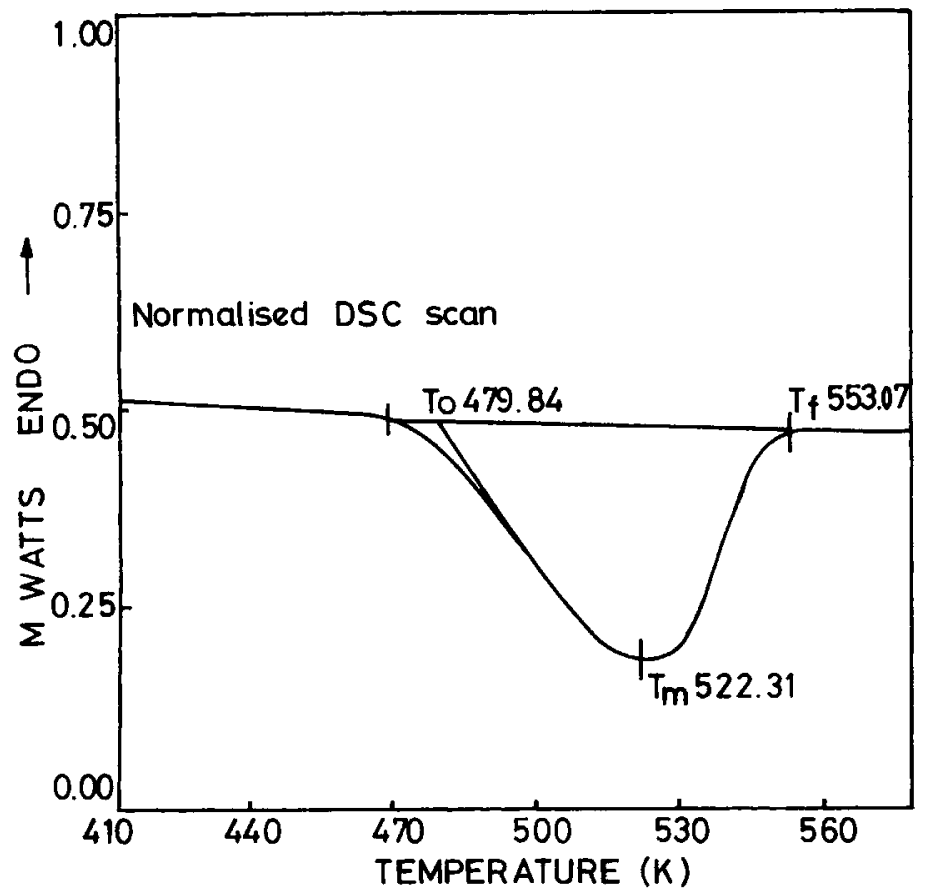

Fig. 4. DSC scan at $10 \mathrm{~K} / \mathrm{min}$ indicating peak onset $\left(T_{o}\right)$, peak minimum $(T m)$ and peak final $\left(T_{j}\right)$ temperatures.

In order to measure gel time characteristics of the resin system, test tube gel time method is followed. About 5-10 $\mathrm{g}$ of the resin mix is taken in a tube provided with a spiral wire for necessary agitation. This is introduced into a thermostatically controlled bath maintained at a specific temperature. The mixture is allowed to attain thermal equilibrium and then the spiral wire is mechanically moved up and down. The viscosity of the resin system gradually increases with time and a rubbery mass is formed, when the movement of the wire gets arrested. The time taken for the entire process is noted as the gel time.

Viscosity measurements are made using Brookefield viscometer. Differential Scanning Calorimeter DSC-2C with data station (Perkin Elmer) and Thermogravimetric analyser TA HE-20 (Mettler) are used for thermal characterisation and kinetic studies. All thermal analyses are carried out in nitrogen atmosphere at a flow rate of $20 \mathrm{~mL} / \mathrm{min}$. Vicat softening is measured according to DIN 53460. The other physical, mechanical and electrical measurements are carried out as per IS : 1998 specifications.

\section{RESULTS AND DISCUSSION}

\section{Resin-Hardener Stoichiometry}

A known quantity of the resin sample was mixed thoroughly with different proportions of the hardener. About $10 \mathrm{mg}$ of the sample was pressed in alu- 


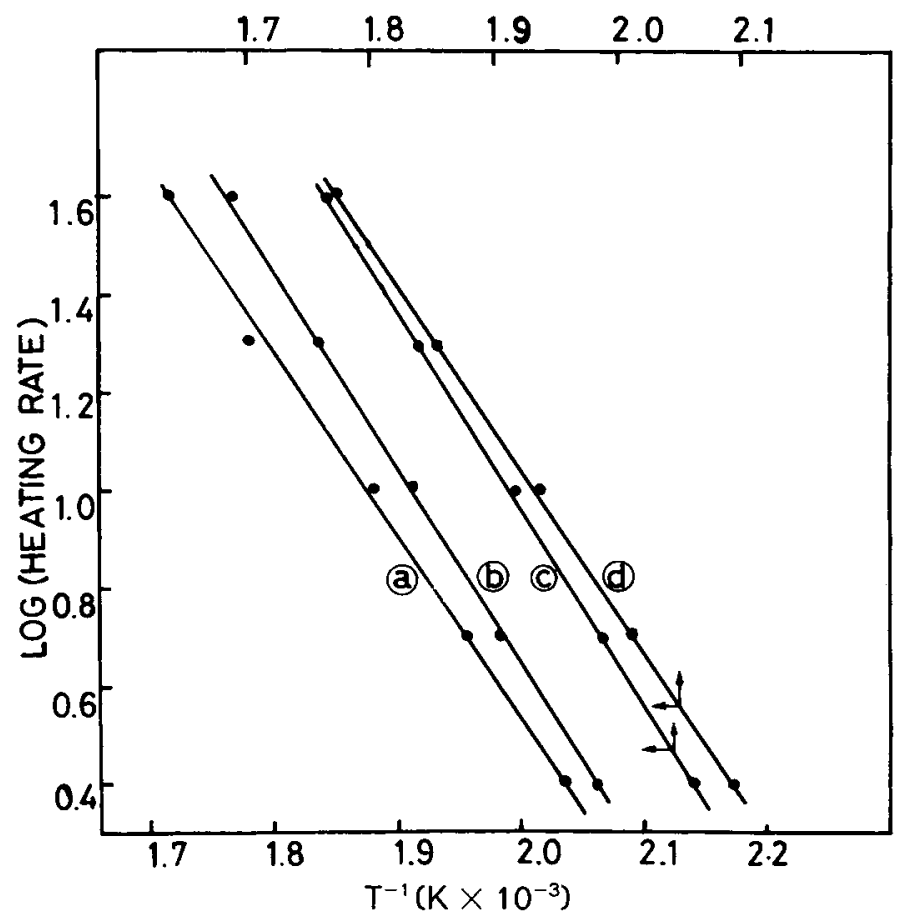

Fig. 5. Activation energy plots at $T m$ values of DSC cure exotherms for (a) control system, (b) $0.5 \% \mathrm{Co}(\mathrm{acac})_{3}$, (c) $1.0 \% \mathrm{Co}(\mathrm{acac})_{3}$, (d) $1.5 \% \mathrm{Co}(\mathrm{acac})_{3}$.

minium sample pans and subjected to dynamic DSC runs at a heating rate of $40 \mathrm{~K} / \mathrm{min}$ in the temperature range of $315-625 \mathrm{~K}$. The observed enthalpy change $\Delta \mathbf{H}$ was plotted against the amounts of the hardener used (Fig. 1). For the resin-hardener ratio of $1: 1$ a maximum value of $\Delta H$ was observed. In actual commercial applications epoxy systems are generally used with a suitable filler. Therefore in the present study silica floor is used; the control system has the formulation resin, hardener and filler in the ratio of $1: 1: 3$.

TABLE II

Kinetic Parameters with Cure Schedules for Epoxy-Anhydride Resin System with Different Concentrations of $\mathrm{Co}(\mathrm{acac})_{3}$

\begin{tabular}{|c|c|c|c|c|}
\hline \multirow[b]{2}{*}{ Parameter } & \multicolumn{4}{|c|}{ Concentration of $\mathrm{Co}(\mathrm{acac})_{3}(\%)$} \\
\hline & 0 & 0.5 & 1.0 & 1.5 \\
\hline \multicolumn{5}{|l|}{ Energy of activation $\left(\mathrm{kJ}^{\mathrm{g}} \mathrm{g}^{-1}\right)$} \\
\hline (a) Dynamic method & 67 & 78 & 77 & 67 \\
\hline (b) Isothermal method & 59 & 57 & 55 & 56 \\
\hline $\mathrm{Z}\left(\times 10^{6} \mathrm{~min}^{-1}\right)$ & $3.2-4.5$ & $3.1-3.8$ & $1.6-2.0$ & $0.9-1.1$ \\
\hline$k\left(\times 10^{-3} \min ^{-1}\right)$ at $453 \mathrm{~K}$ & 17.4 & 25.6 & 29.1 & 32.3 \\
\hline \multicolumn{5}{|l|}{ Cure time $t_{f}(\mathrm{~min})$ at $453 \mathrm{~K}$} \\
\hline (a) Dynamic method & $110-150$ & $90-120$ & $70-110$ & $60-90$ \\
\hline (b) Isothermal method & 140 & 92 & 75 & 69 \\
\hline
\end{tabular}




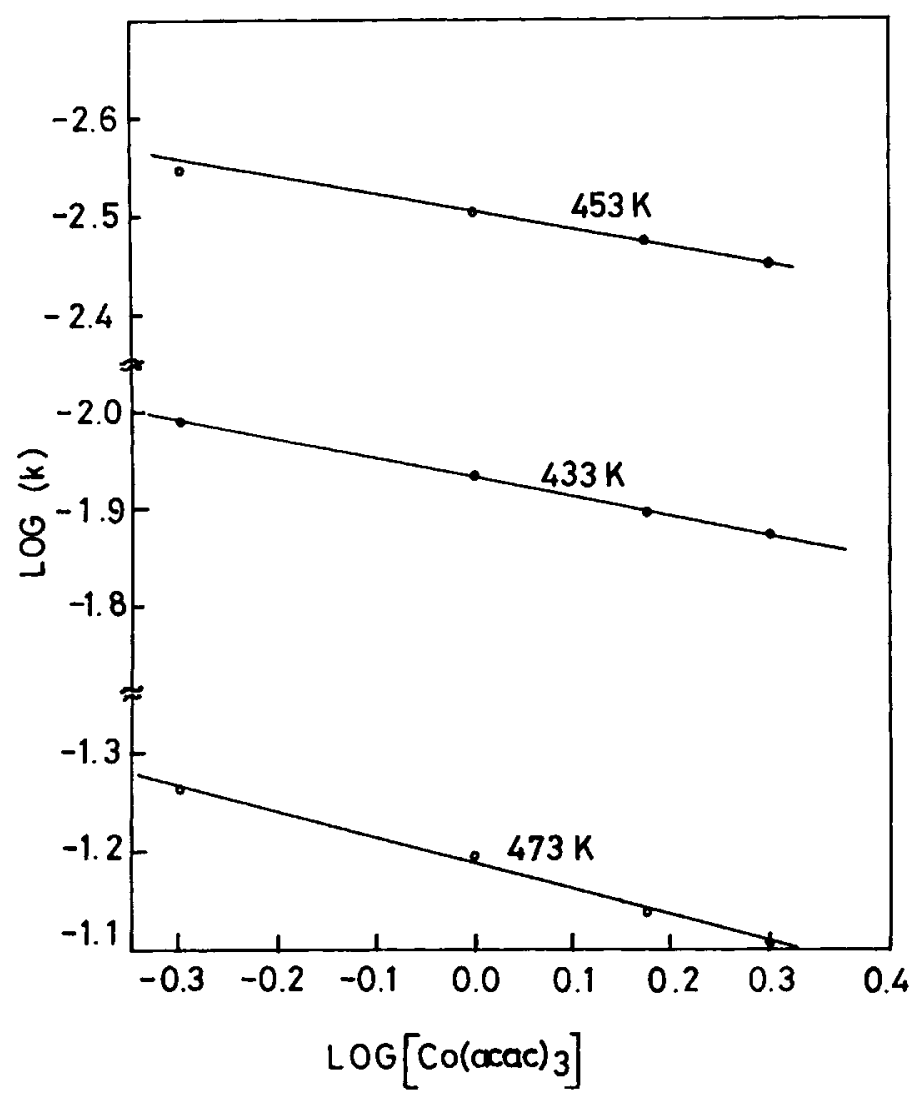

Fig. 6. Log rate constant against concentrations of $\mathrm{Co}(\text { acac })_{3}$ at different temperatures.

\section{Effect of $\mathrm{Co}(\operatorname{acac})_{3}$}

The acceleration of curing of the resin system in presence of the metal chelate has been observed with the shift in the cure exotherm ( Tm) towards the lower temperature as its concentration increases (Fig. 2). It is observed that the Tm values decrease significantly with increase in the concentration up to $1 \%$ by weight of the resin and thereafter remain almost constant. Hence in the present study the concentration of $\mathrm{Co}$ ( acac $)_{3}$ has been limited to $1.5 \%$.

The effect of the metal chelate concentrations on the gel time at various temperatures is given in Table I, which shows that the gel time values for the system in the presence of $\mathrm{Co}$ (acac) $)_{3}$ are considerably lower as compared to those of the control system.

Viscosity measurements (Table I) monitored over a period of time at $298 \mathrm{~K}$ suggest that the storage life of the catalysed system was not affected appreciably at $0.5 \%$ of $\mathrm{Co}(\text { acac })_{3}$. This is confirmed by DSC cure exotherm profiles of samples drawn periodically during the period of 100 days. As is evident from Figure 3, the $T m$ values do not change much for the curing system with $0.5 \%$ $\mathrm{Co}(\text { acac })_{3}$ till 80 days, whereas higher concentrations beyond $0.5 \%$ show decrease in the Tm values. 


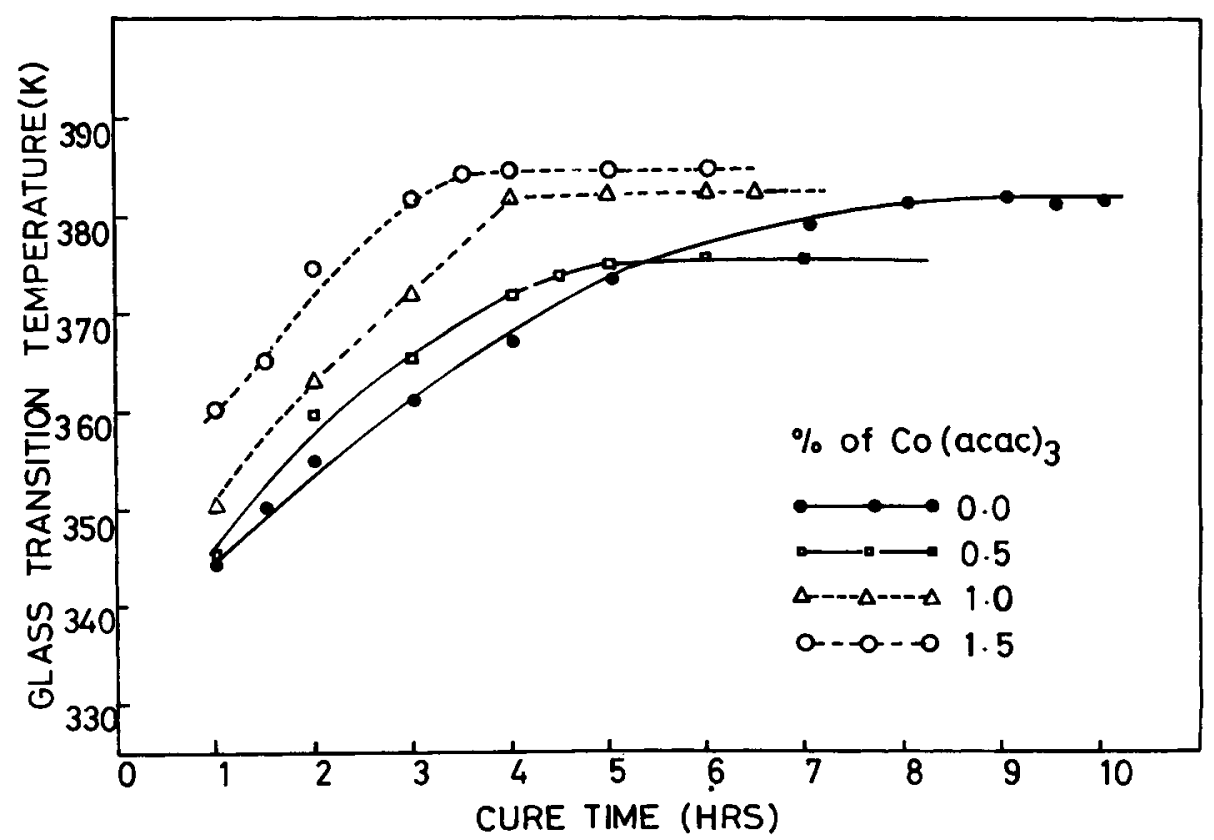

Fig. 7. Glass transition temperature data against cure time for Epoxy anhydride system with different concentrations of $\mathrm{Co}(\mathrm{acac})_{3}$.

\section{Kinetics}

The dynamic DSC scans of the epoxy systems were carried out in the temperature range $315-650 \mathrm{~K}$ at varying heating rates from 2.5 to $40 \mathrm{~K} / \mathrm{min}$. The temperatures corresponding to the peak onset ( $T o$ ) the peak minimum $(T m)$ and the peak final $\left(T_{f}\right)$ of the curing exotherm were determined at various concentrations of the metal chelate. One such exotherm is given in Figure 4.

The order of the curing reaction $(n)$ was calculated using the following rate constant expression. ${ }^{17}$

$$
k=\frac{\Delta H^{n-1} d H / d t}{\left(\Delta H-H_{p}\right)^{n}}
$$

where, $d H / d t$ is the height of the ordinate of the DSC scan at a given temperature.

$H_{p} \quad$ is the partial heat change

$\Delta H \quad$ is the net heat change.

By substituting the values of $n$ from 0.5 to 2.5 a best linear regression fit for $\log k$ against $T^{-1}$ is observed for $n=1$ at varied heating rates.

The activation energy $(E)$ for the curing reaction is calculated by plotting $\log$ (heating rate) against $T^{-1}$ (Fig. 5 ). Using these values the pre-exponential factor $(Z)$ and also the rate constant $(k)$ are evaluated employing the following expressions ${ }^{18-19}$ and the results are compiled in Table II. 
TABLE III

Physical, Mechanical, Thermal and Electrical Properties for Epoxy-Anhydride Resin System with Different Concentrations of Co(acac) ${ }_{3}$

\begin{tabular}{|c|c|c|c|c|}
\hline \multirow[b]{2}{*}{ Properties } & \multicolumn{4}{|c|}{ Concentrations of $\mathrm{Co}(\mathrm{acac})_{3}(\%)$} \\
\hline & 0 & 0.5 & 1.0 & 1.5 \\
\hline \multicolumn{5}{|l|}{ Physical: } \\
\hline \multicolumn{5}{|l|}{ Specific gravity $(\mathrm{gm} / \mathrm{cc})$ at } \\
\hline $298 \mathrm{~K}$ & $1.181-1.184$ & $1.179-1.184$ & $1.181-1.183$ & $1.181-1.183$ \\
\hline \multicolumn{5}{|l|}{ Mechanical: } \\
\hline \multicolumn{5}{|l|}{ Impact strength unnotched } \\
\hline $\begin{array}{l}\text { Flexural strength } \\
\quad\left(\mathrm{kg}^{\left.-\mathrm{cm}^{-1}\right)}\right.\end{array}$ & $960-1025$ & $960-1050$ & $960-1050$ & $960-1050$ \\
\hline \multicolumn{5}{|l|}{ Thermal: } \\
\hline $\begin{array}{l}\text { Specific heat (by DSC; } \\
\text { J/g.deg) }\end{array}$ & \multicolumn{3}{|c|}{ Specific heat (by DSC; } & 1.30 \\
\hline \multicolumn{5}{|l|}{ Decomposition temperature } \\
\hline \multicolumn{5}{|l|}{ Electrical ${ }^{*}$} \\
\hline $50 \mathrm{~Hz}$ at $298 \mathrm{~K}$ & $0.009-0.013$ & $0.005-0.013$ & $0.006-0.014$ & $0.006-0.02$ \\
\hline at $363 \mathrm{~K}$ & 0.0338 & 0.0366 & 0.0321 & 0.037 \\
\hline Dielectric constant & $4.6-5.4$ & $4.5-5.2$ & $4.5-5.2$ & $4.3-5.0$ \\
\hline $\begin{array}{l}\text { Volume resistivity }\left(\times 10^{14}\right. \\
\text { ohm-cm) }\end{array}$ & $8.7-9.1$ & $8.0-8.6$ & $8.8-9.7$ & $7.0-8.0$ \\
\hline $\begin{array}{l}\text { Dielectric strength in } \\
\text { transformer oil } \\
(\mathrm{kV} / \mathrm{mm}) \text { at } 298 \mathrm{~K}\end{array}$ & 15 & 15 & 15 & 15 \\
\hline
\end{tabular}

* Electrical properties were evaluated for circular discs of about $3 \mathrm{~mm}$ thick, cured for $10 \mathrm{~h}$ at $423 \mathrm{~K}$.

$$
\begin{aligned}
Z & =\beta E / R T^{2} \exp (E / R T) \\
\text { and } k & =Z \exp (-E / R T)
\end{aligned}
$$

where $\beta$ is the heating rate and $R$ is the gas constant.

The rate constant increases with increase in concentration of the metal chelate and the order with reference to $\mathrm{Co}(\mathrm{acac})_{3}$ is found to be 0.2 (Fig. 6).

\section{Evaluation of Cure Schedules}

By considering the degradation process as a simple chemical reaction, Toop ${ }^{20}$ has derived the following mathematical expression to evaluate the thermal life of wire enamels and also several reports are available for this purpose based on thermal analytical techniques. ${ }^{21-23}$

$$
\log t_{f}=\frac{E}{2.303 R \theta}+\log \frac{E P\left(x_{f}\right)}{\beta R}
$$


where $\log P\left(x_{f}\right) \approx-2.315-0.547 \mathrm{E} / R T_{f}$

$E=$ energy of activation

$R=$ gas constant

$T_{f}=$ temperature at which specific change is observed

$\beta=$ heating rate

$\theta=$ thermal condition

$t_{f}=$ time to condition at temperature $\theta$.

For various insulating materials the thermal ratings were evaluated from TGA thermograms run at varied heating rates. ${ }^{20,24-26}$

The curing of epoxy system is a process wherein one or more kinds of reactants are transferred from a low molecular weight materials to a crosslinked network. As the curing process is shown to follow the same mechanism throughout the extent of reaction, Toop's equation is extended to find the time to cure of epoxies. ${ }^{26}$ The values of $E$ and $T_{f}$ determined from dynamic DSC cure exotherm at different heating rates are substituted in the above equation and the range of cure schedules are calculated (Table II). It is found that the results for the control system are in accordance with the values reported elsewhere. ${ }^{27}$

From the isothermal DSC scans, the cure times for various concentrations of the systems were recorded at different temperatures. The curing rates were calculated and a plot of $\log$ ( rate) against $\log \mathrm{Co}(\text { acac })_{3}$ gave a straight line, from which the order with respect to metal chelate was found to be 0.25 . It was also: observed that the order remained the same at different temperatures between 453 to $483 \mathrm{~K}$. The energy of activation for the isothermal runs was calculated from time and temperature data (Table II) and are comparable to those obtained by the dynamic scans.

The epoxy system after gelation was post-cured at $423 \mathrm{~K}$ and the glass transition temperature $\left(T_{g}\right)$ was monitored at regular intervals (Fig. 7 ), from which it is inferred that the time required to attain maximum $T_{g}$ gradually decreases with metal chelate concentration and the results are found in good comparison with the cure time evaluated by the above techniques. Similar observations were made when softening point and Rockwell hardness measurements were monitored during curing of epoxy systems in the presence of the metal chelate.

Normally when a metallic impurity is added to an insulating material the thermal stability and the other properties will be affected. But at the concentrations of $\mathrm{Co}$ (acac) $)_{3}$ incorporated into these epoxy systems, no appreciable change in the decomposition temperature (at $10 \%$ weight loss) was observed when the cured samples were subjected to dynamic TGA runs under oxygen atmosphere. Also the physical, mechanical and electrical properties of the systems (Table III) are unaltered by the addition of $\mathrm{Co}(\mathrm{acac})_{3}$.

\section{CONCLUSIONS}

The addition of $\mathrm{Co}(\mathrm{acac})_{3}$ to the resin system decreases the cure time. The overall cure process follows first order kinetics, and the order with respect to the metal chelate is found to be 0.25 . At the concentration levels studied, 
$\mathrm{Co}(\mathrm{acac})_{3}$ does not influence the physical, mechanical, thermal and electrical properties of the resin-hardener system.

The authors wish to thank Mr. S. Sridhar, Scientific Officer and Dr. M. Ramamoorty, Director General, Central Power Research Institute for their useful suggestions and constant encouragement during the course of this work.

\section{References}

1. J. D. B. Smith, J. Appl. Polym. Sci., 26, 979-986 (1981).

2. W. J. Belanger, U.S. Pat. 2,928,807 (to Devoe and Raynolds Co.) (March 1960).

3. H. L. Vincent, C. L. Frye, and P. E. Oppliger, Adv. Chem. Ser., 92, 164 (1970).

4. S. H. Langer and I. N. Elbling, Ind. Eng. Chem., 49, 113 (1957).

5. S. H. Langer, I. N. Elbling, A. B. Finestone, and W. R. Thomas, J. Appl. Polym. Sci., V. 15, 370-374 (1961).

6. J. D. B. Smith, J. Appl. Polym. Sci., 23, 1385-96 (1979).

7. J. D. B. Smith, Am. Chem. Soc. Symposium Series, No. 114, Ch. 3, 48-56 (1979).

8. A. J. Landua, Am. Chem. Soc. Div. Org. Coatings Plast. Chem. Prepr., 24 (2), 299 (Sept. 1964).

9. H. Starck and F. Schlenker, U.S. Pat. 2,801,228 (1957).

10. M. Naps, U.S. Pat. 2,876,208 (1959).

11. M. Markovitz, U.S. Pat. $3,812,214$ (1973).

12. D. M. Stoakley and St. Clair, J. Appl. Polym. Sci., 31, 225-236 (1986).

13. J. D. B. Smith and A. I. Bennett, IEEE International Symposium on Elecl. Insul. $80 \mathrm{CH}$ 1496, EI, 136-139 (1980).

14. J. D. B. Smith and R. N. Kauffman, IEEE Trans. Electr. Insul., EI-19, No. 1 (1984).

15. Y. Song, X. Peng, X. Song, and R. Li, Yingyong Huaxue, 5 (3), 19-22 (1988); Chem. Abstr., 109, 171511r (1988).

16. B. E. Bryant and W. C. Fernelius, Inorg. Synthesis, 5, 188 (1957).

17. H. J. Borchardt and F. Daniels, J. Amer. Chem. Soc., 79, 41 (1957).

18. T. Ozawa, J. Therm. Anal., 2, 301 (1970); 7, 601 (1975).

19. H. E. Kissinger, Anal. Chem., 29, 1702 (1957).

20. D. J. Toop, IEEE Trans. Electr. Insul., EI-6, No. 2 (1971).

21. D. J. David, Insulation, 38 (Nov. 1967).

22. G. P. Brown, D. T. Haarr, and M. Metley, Thermo. Chim. Acta., 1, 441 (1970).

23. L. Krizanovsky and V. Mentlik, J. Therm. Anal., 13, 57 (1978).

24. S. W. Shalaby in Thermal characterisation of polymeric materials (E. A. Turi, Ed.) Academic Press, New York, Ch. 3. (1981).

25. P. V. Reddy, R. Thiagarajan, and K. S. A. Sastry, Annual Seminar on Electrical Insulation, Bangalore, India. 21-22 June, 1985.

26. R. Thiagarajan, P. V. Reddy, S. Sridhar, and M. C. Ratra, J. Therm. Anal, to appear.

27. Araldite Casting and Impregnating Resin Systems, CIBA-GEIGY Instruction Manual.

Received April 20, 1989

Accepted November 6, 1989 